\title{
Mathematical Epidemiology: Possible Improvements to Alert systems
}

\author{
Carlos Polanco*
}

National Institute of Medical Sciences and Nutrition Salvador Zubiran, Mexico

Corresponding author: Carlos Polanco, National Institute of Medical Sciences and Nutrition Salvador Zubiran, Mexico, Tel: 817-735-2454, E-mail: polanco@unam.mx

Received: January 23, 2018; Accepted: February 17, 2018; Published: February 23, 2018

Citation: Polanco C (2018) Mathematical Epidemiology: Possible Improvements to Alert systems. J Prev Med Vol.3 No.1: 8.

Copyright: (C) 2018 Polanco C. This is an open-access article distributed under the terms of the Creative Commons Attribution License, which permits unrestricted use, distribution, and reproduction in any medium, provided the original author and source are credited.

\section{Letter to Editor}

Epidemiological alerts are activated when there is a minimum number of subjects whose laboratory tests confirm they are infected [1], and the number of confirmed cases depends on the nature of the infection. This means the epidemiological alert does not correspond to a predictive system, and in fact, the outbreak is already spreading at the time the alert is activated. Is it possible to minimize the spread of an outbreak? This will depend on how quickly the alert is activated, for instance, in the year 2014 the Ebola outbreak alert was activated with a two month delay. This has probably been the cause that the outbreak became pandemic [2].

A predictive system [3], based on clinical variables strongly associated with the outbreak process, is not reliable by its very nature. The population will distrust a predictive alert, and most likely, the authorities responsible for activating it will wait until receiving some sort of confirmation. On the other hand, a deterministic system based on clinic evidence consumes time while the infectious agent disseminates. Is it possible to have a predictive-deterministic system that emits early alerts weighing the two aspects? [4]. This type of mathematical model has a greater chance of being implemented, as the origin of the alert would have both clinical and non-clinical aspects.

How can alert systems be improved with technology? The spreading of an epidemic outbreak can be substantially reduced if the population use electronic mini-sensors that collect biometric data (as high temperature, or fever), and transmit the information wirelessly to computers [5]. This information would provide the database of symptoms and clinical information that now is only available from patients that go to hospitals.

In 2014 the resurgence of Ebola virus disease in Africa was related to people crossing the borders on a daily basis. The improvement in means of transport, and the expansion of roads, and highways significantly increase the interaction of individuals and the chance of infection. In my view, a system where the information of people at risk is constantly monitored would make surveillance easier and would reduce the response time, making it possible to issue an early alert [6].

Response time reduction is a significant issue in the control of an epidemic outbreak. In my view, it is necessary to implement active surveillance systems, instead of passive ones, initially in small villages or towns, where other outbreaks have occurred, and then expand it. This means that the alert must not depend only on patients that come to hospitals for treatment. In developing countries, auto medication is very high as there are not enough hospitals to go to, or they are very far from villages, therefore, an active system transmitting information about the patient's symptoms, in real time, would be very helpful to the health system that would check the patient instead of waiting for him to go to a health institution.

An active system implies an unprecedented effort, hence, it would be necessary to have the cost of the biometric sensors very low so they can be supplied to the population free of charge. In order to achieve this source of energy of the device could be based on movement or solar energy. Of course other factors also affect the total cost of implementation of this strategy, but the direct cost of the portable sensor is very important, if that cost is negligible, then it is feasible implementation.

Dr. Carlos Polanco is a mathematician with specialization in parallel computing. He has spent the last 10 years developing computational mathematical algorithms focused on Mathematical Epidemiology. $\mathrm{He}$ is Senior Lecturer of the Department of mathematics in the Faculty of Sciences at the Universidad Nacional Autónoma de México.

\section{References}

1. Mclnerney JE, Richter A (2011) Strengthening hospital preparedness for chemical, biological, radiological, nuclear, and explosive events: Clinicians' opinions regarding physician/ physician assistant response and training. Am Disaster Med 6: 7387.

2. Glennon EE, Restif O, Sbarbaro SR, Garnier R, Cunningham AA, et al.(2017) Domesticated animals as hosts of henipaviruses and filoviruses: A systematic review. Vet J.

3. Lekone PE, Finkenstadt BF (2006) Statistical inference in a stochastic epidemic SEIR model with control intervention: Ebola as a case study. Biometrics 62: 1170-1177.

4. Polanco C, Castañón-González JA, Macías AE, Samaniego JL, Buhse T, et al. (2013) Detection of severe respiratory disease epidemic outbreaks by CUSUM-based overcrowd-severe-respiratorydisease-index model. Comput Math Methods Med 2013: 1-9. 
5. Bajwa M (2014) Emerging 21st century medical technologies. Pak J Med Sci 30: 649-655
6. Polanco C, Islas VI, Castañón González JA, Buhse T, Arias-Estrada $M$, et al. (2017) Electronic devices that identify individuals with fever in crowded places: A prototype. micromachines 8: 202. 